\title{
Listeria spp. ocorrência em equipamentos e ambientes de processamento de carne bovina
}

\section{Listeria spp. occurrence in equipments and processing plants of meat}

\author{
Márcia de Aguiar Ferreira Barros ${ }^{1 *}$; Vanerli Beloti ${ }^{2}$; Marise Mineko Haga ${ }^{3}$; Lívia \\ Cavaletti ${ }^{3}$; Loredana d'Ovídio ${ }^{3}$; Fabrício Amorim Monteiro ${ }^{3}$; Luís Augusto Nero ${ }^{4}$
}

Resumo

O objetivo desta pesquisa foi estabelecer a ocorrência de Listeria monocytogenes em diversos pontos de plantas de processamento de carne bovina em 01 abatedouro e 05 casas de carnes localizados na região norte do Paraná. Para a detecção de Listeria spp. em 124 amostras de equipamentos/utensílios e instalações, utilizou-se a metodologia preconizada pelo United States Departament of Agriculture (USDA), com identificação das espécies por testes bioquímicos e posterior confirmação pelo API Listeria (bioMérieux). Os resultados obtidos indicaram freqüências de $6,25 \%$ de L. monocytogenes; $68,75 \%$ de $L$. innocua $; 18,75 \%$ de $L$. welshimeri; $4,17 \%$ de $L$. seeligeri e $2,08 \%$ de $L$. grayi. As amostras positivas para L. monocytogenes tiveram origem em equipamentos de casa de carnes como caixas plásticas e amaciador. Palavras-chave: Listeria monocytogenes, processamento de carne, equipamentos, planta de processamento de carne.

\begin{abstract}
The goal of this research was to establish the occurrence of Listeria monocytogenes in several points of meat processing plants such as 01 slaughterhouse and 05 butcher's shops sited at north region of Paraná State. The United States Department of Agriculture (USDA) isolation methodology of Listeria spp. was used in 124 samples of equipments/utensils and environmental sources, with species identification by biochemical tests and confirmation by API Listeria (bioMérieux). The results showed frequencies of $6,25 \%$ for $L$. monocytogenes; $68,75 \%$ for $L$. innocua; 18,75 for $L$. welshimeri; $4,17 \%$ for $L$. seeligeri and $2,08 \%$ of $L$. grayi. The positive samples for $L$. monocytogenes were equipments of butcher's shops, as plastic boxes and tendering machine.

Key words: Listeria monocytogenes, meat processing, environmental sources, meat processing plant.
\end{abstract}

\footnotetext{
1 Laboratório de Inspeção de Produtos de Origem Animal, Departamento de Medicina Veterinária Preventiva, CCA, UEL, Londrina, PR Brasil; Doutoranda do Programa de Pós-graduação em Ciência Animal, UEL, Londrina, PR, Brasil. Tel: 433337 2257; Fax: 43 3371 4714. Autor para correspondência. E-mail: mafer@folhaweb.com.br.

2 Médica Veterinária, Laboratório de Inspeção de Produtos de Origem Animal, Professora Dra. Departamento de Medicina Veterinária Preventiva, CCA, UEL, Londrina PR Brasil.

3 Alunos de graduação de Medicina Veterinária, estagiários do LIPOA, DMVP, CCA, UEL, Londrina PR Brasil.

4 Doutorando do Programa de Pós-graduação em Ciência dos Alimentos, FCF, USP, São Paulo SP Brasil.

* Autor para correspondência
} 


\section{Introdução}

Listeria spp. é um bacilo gram positivo, mesófilo, não esporulado, anaeróbio facultativo e intracelular facultativo. $\mathrm{O}$ gênero está representado por seis espécies: monocytogenes, innocua, ivanovii, seeligeri, welshimeri, grayi e murray, mas apenas L. monocytogenes tem sido relatada causando doença em humanos (JAY, 2000). Os habitats primários de L. monocytogenes são o solo e vegetais em decomposição, nos quais pode desenvolver-se como saprófita. Apresenta ampla distribuição e provavelmente por isso contamine com freqüência os alimentos durante a produção ou processamento dos mesmos (KONEMAN, 2001). Diferente de outros patógenos apresenta características psicrotróficas, podendo multiplicar-se em alimentos refrigerados, aumentando desta forma o risco de listeriose em proporção direta com a crescente produção de alimentos frescos e prontos para o consumo (WILKINS; BOURGEOIS; MURRAY, 1972; ALMEIDA; ALMEIDA; RODRICK, 1999).

Embora exista uma margem de risco para todos os consumidores, este patógeno é de extrema importância devido a sua forte associação com septicemia, encefalite, meningite e altos índices de mortalidade entre neonatos, idosos e imunocomprometidos e ainda, abortos em gestantes (SCHUCHAT; DEAVER; GER, 1992; ROCOURT, 1994; HOFER, 1984, 1998; SNYDER, 1995). Está claro que apesar de muitos indivíduos consumirem alimentos contaminados com L. monocytogenes, a incidência de listeriose é relativamente baixa (FARBER; ROSS; HARWING, 1996; HITCHENS, 1996), pois diversos fatores estão envolvidos na ocorrência da doença, como imunocompetência do hospedeiro e particularidades da amostra envolvida, relacionadas com a virulência dos diversos sorotipos (ROCOURT, 1994; RYSER, 1999). A combinação destes fatores pode ser responsável por aspectos ainda não elucidados da listeriose humana.

A emergência de L. monocytogenes como patógeno alimentar data da década de 1980, com a ocorrência de diversos surtos e casos esporádicos de listeriose ligados ao consumo de alimentos contaminados (LINNAN et al., 1988; BULA; BILLE; GLAUSER, 1988; FARBER; PETERKING, 1991; RYSER; MARTH,1991; MOURA; DESTRO; FRANCO, 1993; SWAMINATH; ROCOURT; BILLE, 1995; FENLON; WILSON; ACHIE, 1996; JAY, 1995, 1996; SILVA et al., 2003) e tem provocado inúmeras discussões em todo o mundo, o que por sua vez tem estimulado pesquisadores a buscar respostas para as várias questões que têm surgido sobre a relação entre Listeria spp. e listeriose.

Após um surto de listeriose ocorrido em 1985 na Califórnia, avaliou-se a participação de produtos cárneos como veículos da infecção, sugerindo que $10 \%$ dos 1600 casos anuais de listeriose nos Estados Unidos resultaram do consumo de produtos cárneos inadequadamente cozidos (SCHWARTZ et al., 1988). $\mathrm{O}$ envolvimento desses alimentos em surtos e casos esporádicos de listeriose humana ficou comprovado em diversos países (KERR; DEALLER; LACEY, 1988; CANTONI; BALZARETTI; VALENTI, 1989; KACZMARSKI; JONES, 1989; FARBER; PETERKIN, 1991; RYSER; MARTH, 1991; BADER, 1993; GOULET et al., 1995; JACQUET et al., 1995).

No Brasil, há relatos da ocorrência de Listeria spp. em alimentos e ambientes, como vegetais (HOFER, 1975a), esgotos (HOFER, 1975b), solo (HOFER; PÓVOA, 1984), camarão (HOFER; RIBEIRO, 1990; DESTRO; LEITÃO; FARBER, 1996), carnes, leite e derivados (DESTRO; SERRANO; KABLIKI, 1991; CASAROTTI; GALLO; CAMARGO, 1994; SILVA; HOFER; TIBANA, 1998; PICHI et al., 1999). Entretanto, deve-se ressaltar que nenhum caso clínico, até o momento, foi associado ao consumo desses alimentos, fato que pode ser atribuído à falta de estrutura dos laboratórios clínicos que não incluem a pesquisa desse patógeno como rotina.

Nos últimos anos a análise de perigos e pontos 
críticos de controle (APPCC) tem sido proposta como a melhor conduta na obtenção de alimentos seguros e, L. monocytogenes está incluída na relação de microrganismos patogênicos alvos do APPCC. A ocorrência deste microrganismo na cadeia de processamento de alimentos é evidenciada pela ampla distribuição nos produtos finais e a contaminação do alimento pode ocorrer em alguma etapa do processo, como a refrigeração que não inibe sua multiplicação (COX et al., 1989).

A incorporação de L. monocytogenes em plantas de processamento de carnes pode ocorrer pela presença de resíduos de terra em calçados, por animais portadores ou que apresentem couro e superfícies contaminados, por alimentos crus de origem animal e possivelmente por portadores humanos assintomáticos. A diversidade deste ambiente possibilita ao microrganismo vários sítios de colonização podendo aderir a vários tipos de superfícies, como aço inoxidável, vidros e borrachas, com formação conseqüente de biofilmes (JEONG; FRANK, 1994). Essas características podem contribuir, a partir de efluentes contaminados, com o aumento e manutenção desse patógeno no meio ambiente.

Os perigos microbiológicos existentes na carne bovina in natura são razoavelmente conhecidos, mas não se dispõe de dados epidemiológicos seguros sobre a origem da contaminação por L. monocytogenes na carne bovina brasileira. Assim, o objetivo desta pesquisa foi verificar a ocorrência de Listeria spp. em equipamentos e instalações de plantas processadoras de carne bovina, avaliando o papel desses pontos como potenciais fontes de contaminação do produto final.

\section{Material e Métodos}

\section{Colheita das amostras}

Foram colhidas 124 amostras de equipamentos/ utensílios e instalações de 06 estabelecimentos processadores de carne bovina, sendo 01 abatedouro de bovinos e 05 casas de carnes, localizados na região norte do Paraná. A técnica utilizada para colheita de amostras foi de esfregaço de superfície com swabs em água peptonada 1\%, utilizando-se moldes estéreis de $50 \mathrm{~cm}^{2}$ e de $30 \mathrm{~cm}^{2}$ (ABNT, 1988). A utilização de cada um dos moldes foi determinada de acordo com a dimensão do ponto amostrado, e quando o formato não permitia a adequação dos moldes (como ganchos) toda a superfície era amostrada.

\section{Pontos amostrados}

No abatedouro foram colhidas amostras das instalações (pisos, paredes e ralos de câmaras frias e linha de abate) e de equipamentos/utensílios (plataformas, mesas, rolo de esfola, serras, ganchos, facas, caixas plásticas e maquinários da sala de embutidos). Nas casas de carnes, também foram coletadas amostras das instalações (pisos de câmara fria e sala de desossa, ralos, paredes, sistemas de refrigeração) e dos equipamentos/utensílios utilizados nos estabelecimentos para manuseio das carnes (mesas, balcões refrigeradores, facas, moedores, amaciadores, serras, estrados de madeira, caixas plásticas, balanças) além de caminhões frigoríficos.

Processamento das amostras

A metodologia utilizada para detecção de Listeria spp. foi a preconizada pelo "United States Departament of Agriculture" (UNITED STATES DEPARTAMENT OF AGRICULTURE, 1996). Para o enriquecimento seletivo primário utilizou-se o caldo base seletivo Listeria (formulação UVM - CM863 Oxoid), com incubação a $30^{\circ} \mathrm{C} / 24 \mathrm{~h}$, seguido de enriquecimento seletivo secundário em caldo Fraser (CM865 Oxoid), com incubação a $35^{\circ} \mathrm{C} / 24-40 \mathrm{~h}$.

Após a fase de enriquecimento, o plaqueamento seletivo diferencial foi feito em Oxford Medium Base (0225 Difco), com incubação a $35^{\circ} \mathrm{C}$ por $24 / 48 \mathrm{~h}$. Quando presentes, pelo menos 05 colônias típicas de cada placa foram estriadas em ágar Tripticase de Soja (0369 Difco), incubadas a $30^{\circ} \mathrm{C}$ por $24 / 48 \mathrm{~h}$, para 
confirmação da morfologia típica de Listeria spp. por transiluminação (Henry's system). As colônias típicas foram submetidas à identificação por testes bioquímicos convencionais (PAGOTTO et al., 2001), e a confirmação dos resultados foi feita utilizando-se API - Listeria (bioMérieux).

Todas as análises foram realizadas no Laboratório de Inspeção de Produtos de Origem Animal (LIPOA) da Universidade Estadual de Londrina, Paraná.

\section{Resultados e Discussão}

A Tabela 1 mostra todos os resultados obtidos nos pontos de amostragem. O isolamento de Listeria spp. foi observado em $48(33,70 \%)$ amostras de equipamentos/utensílios e instalações de plantas processadoras de carne bovina, sendo que $03(6,25 \%)$ amostras foram de L. monocytogenes, 33 (68,75\%) de L. innocua, 09 (18,75\%) de L. welshimeri, 02 (4,17\%) de L. seeligeri e 01 (2,08\%) de L. grayi (Tabela 2).

Tabela 1. Ocorrência de Listeria spp. em 124 amostras de instalações e equipamentos de 01 abatedouro e 05 casas de carnes localizados na região norte do Paraná.

\begin{tabular}{|c|c|c|c|c|c|c|c|}
\hline Pontos de amostragem & $\begin{array}{c}\text { negativos } \\
\mathrm{n}(\%)\end{array}$ & $\begin{array}{l}\text { L. monocytogenes } \\
\text { n (\%) }\end{array}$ & $\begin{array}{l}\text { L. іппосиа } \\
\qquad \mathrm{n}(\%)\end{array}$ & $\begin{array}{l}\text { L. welshimeri } \\
\text { n (\%) }\end{array}$ & $\begin{array}{l}\text { L. seligeeri } \\
\text { n (\%) }\end{array}$ & $\begin{array}{l}\text { L. grayi } \\
\mathrm{n}(\%)\end{array}$ & $\begin{array}{l}\text { Total } \\
\mathrm{n}(\%)\end{array}$ \\
\hline \multicolumn{8}{|l|}{ Abatedouro } \\
\hline Instalações & $03(11,11 \%)$ & - & $04(14,81 \%)$ & - & - & - & $07(25,93 \%)$ \\
\hline Equip./Utens. & $16(59,26 \%)$ & - & $04(14,81 \%)$ & - & - & - & $20(74,07 \%)$ \\
\hline Sub-total 1 & $19(70,37 \%)$ & - & $08(29,63 \%)$ & - & - & - & $27(100,00 \%)$ \\
\hline \multicolumn{8}{|l|}{ Casas de Carnes } \\
\hline Instalações & $16(16,49 \%)$ & - & $09(09,28 \%)$ & $02(02,06 \%)$ & - & $01(01,03 \%)$ & $28(28,87 \%)$ \\
\hline Equip./Utens. & $41(42,27 \%)$ & $03(03,09 \%)$ & $16(16,49 \%)$ & $07(07,22 \%)$ & $02(02,06 \%)$ & - & $69(71,13 \%)$ \\
\hline Sub-total 2 & $57\left(58,76^{\circ} \%\right)$ & $03\left(03,09^{\circ}\right)$ & $25(25,77 \%)$ & $09(09,28 \%)$ & $02\left(02,06^{\circ} \%\right)$ & $01(01,03 \%)$ & $97(100,00 \%)$ \\
\hline \multicolumn{8}{|l|}{ Resumo } \\
\hline Instalações & $19(15,32 \%)$ & - & $13(10,48 \%)$ & $02(01,61 \%)$ & - & $01(00,81 \%)$ & $35(28,23 \%)$ \\
\hline Equip./Utens. & $57(45,97 \%)$ & $03(02,42 \%)$ & $20(16,13 \%)$ & $07(05,65 \%)$ & $02(01,61 \%)$ & - & $89(71,77 \%)$ \\
\hline Total & $76(61,29 \%)$ & $03(02,42 \%)$ & $33(26,61 \%)$ & $09\left(07,26^{\circ}\right)$ & $02(01,61 \%)$ & $01(00,81 \%)$ & $124(100,00 \%)$ \\
\hline
\end{tabular}


Tabela 2. Freqüência de Listeria spp. em 48 amostras positivas de instalações e equipamentos de 01 abatedouro e 05 casas de carnes localizados na região norte do Paraná $(n=124)$.

\begin{tabular}{lc}
\hline Listeria spp. & $\mathrm{n}(\%)$ \\
\hline L. monocytogenes & $03(06,25 \%)$ \\
L. innocua & $33(68,75 \%)$ \\
L. welshimeri & $09(18,75 \%)$ \\
L. seligeeri & $02(04,17 \%)$ \\
L. grayi & $01(02,08 \%)$ \\
\hline Total & $48(100,00 \%)$ \\
\hline
\end{tabular}

No abatedouro isolou-se apenas L. innocua, nos seguintes pontos: piso da câmara fria (1 amostra), ralo da câmara fria (1), ralo da linha de abate (2) e sala de embutidos (4, em moedor, ensacadeira, misturador e caixa plástica). Apenas nas amostras das casas de carnes foram encontradas $L$. monocytogenes, bem como outras espécies de Listeria (Tabela 3). As amostras positivas para $L$. monocytogenes foram provenientes de caixa plástica para armazenamento de cortes em câmara fria (1 amostra), caixa plástica instalada na sala de cortes para recolhimento de pedaços de carne para serem moídos (1) e amaciador (1).

Tabela 3. Resultados obtidos em 40 amostras positivas para Listeria spp. em diferentes pontos de instalações e equipamentos/utensílios de 05 casas de carnes localizadas na região norte do Paraná ( $\mathrm{n}=124)$.

\begin{tabular}{|c|c|c|c|c|c|c|}
\hline Pontos de amostragem & L. monocytogenes & L. іппосиа & L. welshimeri & L. seligeeri & L. grayi & Total \\
\hline \multicolumn{7}{|l|}{ Instalações } \\
\hline Pisos de câmaras frias & - & 3 & 1 & - & - & 4 \\
\hline Ralos & - & 6 & 1 & - & - & 7 \\
\hline \multicolumn{7}{|l|}{ Equip./Utens. } \\
\hline Mesas & - & 2 & 2 & - & - & 4 \\
\hline Balcões refrig. & - & 1 & - & - & - & 1 \\
\hline Facas & - & 2 & - & - & - & 2 \\
\hline Moedores & - & 1 & 1 & - & - & 2 \\
\hline Amaciadores & 1 & - & 1 & - & - & 2 \\
\hline Serras & - & - & 1 & - & - & 1 \\
\hline Estrados de madeira & - & 3 & - & - & - & 3 \\
\hline Caixas plásticas (câm. fria) & 1 & 3 & 1 & 2 & - & 7 \\
\hline Caixas plásticas (cortes) & 1 & 2 & - & - & 1 & 4 \\
\hline Balanças & - & - & 1 & - & - & 1 \\
\hline Equip. de embutidos & - & 2 & - & - & - & 2 \\
\hline Total & 3 & 25 & 9 & 2 & 1 & 40 \\
\hline
\end{tabular}


A presença de L. innocua, apesar de considerada não-patogênica, não deve ser subestimada já que alguns autores apontam a possibilidade da mesma ser um possível indicador da presença de $L$. monocytogenes (HEIN et al., 2001; CAPITA et al., 2001) e nossos resultados indicaram alta ocorrência (68,75\%) de L. innocua (Tabela 2) tanto em instalações quanto em equipamentos/utensílios como ralos, pisos, estrados de madeira de câmaras frias, moedores, mesas, facas, balcões refrigeradores, caixas plásticas, misturadores e embutideiras (Tabela 3). De acordo com Waldroup (1996) a detecção de qualquer outra espécie de Listeria seria indicativo da presença de L. monocytogenes.

Em trabalho realizado por Picchi et al. (1999), avaliando a ocorrência de Listeria spp. em quartos dianteiros de bovinos, 96\% das amostras foram positivas, sendo $20 \%$ de L. monocytogenes e $56 \%$ de L. innocua e os autores ressaltam a importância do controle da carne na sua origem e também nos procedimentos da desossa, no sentido de eliminar e/ ou reduzir o microrganismo na carne in natura e nos derivados, com adoção de medidas específicas na obtenção e processamento da carne além daquelas práticas rotineiras de higiene empregadas nas indústrias.

Os resultados obtidos em nossa pesquisa confirmam ainda, a característica psicrotrófica de Listeria spp., já que 23 amostras positivas foram provenientes de equipamentos/utensílios e instalações de câmaras frias, e por esta capacidade de desenvolvimento a baixas temperaturas pode-se esperar a sobrevivência do patógeno por longos períodos nos alimentos e no ambiente.

Os resultados obtidos ainda apontam as caixas plásticas como importantes pontos de contaminação, já que todas as espécies identificadas de Listeria foram isoladas desse equipamento/utensílio (Tabela 3 ). As características dessas caixas (material plástico vazado) permitem a aderência de matéria orgânica e dificultam a higienização adequada, possibilitando a formação de biofilmes.
A ampla distribuição de Listeria spp. em equipamentos/utensílios e instalações de processamento da carne bovina, tanto no abate quanto no ponto de venda, ficou claramente estabelecida pelos resultados apresentados e tornase preocupante ao se observar a presença de $L$. monocytogenes em equipamentos de processamento final do produto que será adquirido pelo consumidor.

\section{Conclusão}

A contaminação de plantas de processamento da carne bovina por Listeria spp. e a presença de $L$. monocytogenes em equipamentos/utensílios pode representar risco ao consumidor, pela possibilidade de incorporação do patógeno no produto final. Nossos resultados ainda revelam os principais pontos de contaminação no processamento de produtos cárneos, o que pode servir como subsídio para órgãos oficiais de saúde na adoção de medidas necessárias para eliminação ou redução de riscos associados a esse patógeno, além de conscientização do pessoal envolvido no processamento da carne, incentivando as boas práticas na produção. Pesquisas relacionando a presença de L. monocytogenes na linha de produção da carne bovina e no produto final estão sendo conduzidas e em fase de conclusão.

\section{Referências}

ALMEIDA, P. F.; ALMEIDA, R. C. C.; RODRICK, G. E. Listeria monocytogenes: importância e distribuição nos alimentos. Higiene Alimentar, São Paulo, v.13, n.64, p.1923, 1999.

ASSOCIAÇÃO BRASILEIRA DE NORMAS TÉCNICAS. Preparo da amostra para exame microbiológico: NBR 10203. Rio de Janeiro: ABNT, 1988.3p.

BADER, J. M. Source of listeriosis outbreaks in France. Lancet, Minneapolis, v.341, n.8843, p.341-487, feb. 1993.

BULA, C.; BILLE, J.; GLAUSER, M. P. Epidemic foodborne listeriosis in western Switzerland: description of the 58 adult cases. American Society for Microbiology, Washington, p.35, 1988. 
CANTONI, C.; BALZARETTI, C.; VALENTI, M. A case of $L$. monocytogenes human infection associated whit consumption of "testa in cascetta" (cooked meat pork product). Archivio Veterinario Italiano, Milano, n.40, p.141-142, 1989.

CAPITA, R.; ALONSO-CALLEJA, C.; MORENO, B.; GARCIA-FERNÁNDEZ, M. C. Ocurrence of Listeria species in retail poultry meat and comparison of a cultural/ immunoassay for their detection. International Journal of Food Microbiology, Amsterdam, v.65, p.75-82, 2001.

CASAROTTI, V. T.; GALLO, C. R.; CAMARGO, R. Ocorrência de Listeria monocytogenes em leite cru, leite pasteurizado tipo $\mathrm{C}$ e queijo Minas frescal comercializado em Piracicaba, SP. Arquivo Latinoamericano de Nutrição, v.44, n.3, p.158-163, 1994.

COX, L. J.; KLEISS, T.; CORDIER, J. L.; CORDELLANA, C.; KONKEL, P.; PEDRAZZINI, C., BEUMER, R.; SIEBENGA, A.. Listeria spp. in food processing, nonfood and domestic environments. Food Microbiology, London, v.8, p.968-977, 1989.

DESTRO, M. T.; SERRANO, A. M.; KABLIKI, D. Y. Isolation of Listeria species from some Brazilian meat and dairy products. Food Control, Guildford, v.2, p.110-112, 1991.

DESTRO, M. T.; LEITÃO, M. F. F.; FARBER, J. M. Use of molecular typing methods to trace the dissemination of Listeria monocytogenes in a shrimp processing plant. Applied And Environmental Microbiology, Washington, v.62, p.705-711, 1996.

FARBER, T. M.; PETERKIN, P. I. Listeria monocytogenes: a food-borne pathogen. Microbiological Reviews, Washington, v.55, n.3, p.476-511, 1991.

FARBER, J. M.; ROSS, W. H.; HARWING, J. Health risk assessment of Listeria monocytogenes in Canadá. International Journal of Food Microbiology, Amsterdam, v.30, p.145-156, 1996.

FENLON, D. R.; WILSON, J.; ACHIE, W. The incidence and level of Listeria monocytogenes contamination of food sources at primary production and initial processing. Journal of Applied Bacteriology, Oxford, v.81, p.641-650, 1996.

GOULET, V.; REBIERE, I.; MARCHETTI, P.; LEPOUTRE, A.; VEIT, P.; DEHAUMONT, P.; ROCOURT, J. Listeriosis in France: lessons from the investigation of two major national outbreaks. In: INTERNATIONAL SYMPOSIUM ON PROBLEMS OF LISTERIOSIS, 12., 1995, Western. Proceedings... Western, 1995. p.159.

HEIN, I.; KLEIN, D.; LEHNER, A.; BUBERT, A.; BRANDL, E.; WAGNER, M. Detection and quantification of the iap gene of Listeria monocytogenes and Listeria innocua by a new real time quantitative PCR assay. Research in Microbiology, Paris, v.152, p.37-46, 2001.
HITCHENS, A. D. Assessment of alimentary exposure of Listeria monocytogenes. International Journal of Food Microbiology, Amsterdam, v.30, p.71-85, 1996.

HOFER, E. Study on Listeria spp. on vegetables suitable for human consumption. In: CONGRESSO BRASILEIRO DE MICROBIOLOGIA, 6., 1975, Salvador. Resumos... Salvador, 1975.

HOFER, E. Isolamento e caracterização de Listeria monocytogenes em água de esgoto. Memória do Instituto Oswaldo Cruz, São Paulo, v.73, p. 31-38, 1975 b.

HOFER, E.; PÓVOA, M. M. Pesquisa de Listeria monocytogenes em solos. Memória do Instituto Oswaldo Cruz, São Paulo, v.79, n.1 p.45-53, 1984.

HOFER, E.; RIBEIRO, R. Ocorrência de espécies de Listeria em camarão industrializado. Revista de Microbiologia, São Paulo, v.21, n.2, p.207-208, 1990.

HOFER, E. Meningite por Listeria monocytogenes. Relato de casos em pacientes do Distrito Federal. Revista da Sociedade Brasileira de Medicina Tropical, Rio de Janeiro, v.31, p.173-177, 1998.

JACQUET, C.; CATIMEL, B.; GOULET, V.; LEPOUTRE, V.; VEIT, P.; DEHAUMONT, P.; ROCOURT, J. Typing of Listeria monocytogenes during epidemiological investigations of the French listeriosis outbreaks in 1992, 1993 and 1995. In: OF THE XII INTERNATIONAL SYMPOSIUMON PROBLEMS OF LISTERIOSIS, 12., 1995, Western. Proceedings ... Wertern, 1995. p.161-176.

JAY, J. M. Food with low numbers of microorganisms may not be the Safest Foods OR, Why did human Listeriosis and Hemorragic Colitis become Foodborne Diseases? Dairy, Food and Environmental Sanitation, Ames, v.15, n.11, p.674-677, nov., 1995.

JAY, J. M. Prevalence of Listeria spp in meat and poultry products. Food Control, Guildford, v.7, n 4/5, p.209-214, 1996.

JAY, J. M. Modern Food Microbiology. 6. ed. Aspen: Gaithersburg, 2000. 854p.

JEONG, D. K.; FRANK, J. F. Growth of Listeria monocytogenes at $10^{\circ} \mathrm{C}$ in biofilms with microorganisms isolated from milk and dairy processing environments. Journal of Food Protection, Des Moines, v.57, p.576$586,1994$.

KACZARMASKI, E. B.; JONES, D. M. Listeriosis in readycooked chicken. Lancet, Minneapolis, v.1, n.8637, p.549, 1989.

KERR, K. G.; DEALLER, S. F.; LACEY, R.W. Materno-fetal listeriosis from cook-chill food. Lancet, Minneapolis, v.2, n.8620, p.1133, 1988.

KONEMAN, E. W. Diagnóstico Microbiológico. 5. ed. Rio de Janeiro: Médica e Científica, 2001. 1465p. 
LINNAN, M. J.; MASCOLA, L; LOU, X. D.; GOULET, V.; MAY, S.; SALMINEN, C.; HIRD, D. W.; YONEKURA, M. L.; HAYES, P.; WEAVER, R. Epidemic listeriosis associated with Mexican-style cheese. New England Journal of Medicine, Boston, v.319, p.823-828, 1988.

MOURA, S. M.; DESTRO, M. T.; FRANCO, B. D. G. M. Incidence of Listeria species in raw and pasteurized milk produced in Sao Paulo, Brazil. International Journal of Food Microbiology, Amsterdam, v.19, p.229-237, 1993.

PAGOTTO, F.; DALEY, E.; FARBER, J.; WARBURTON, D. Isolation of Listeria monocytogenes from all food and environmental samples. Health Canada's - Government of Canada, 2001. Disponível em: <http://www.hc-sc.gc.ca/ food-aliment>. Acesso em: 28 fev. 2004.

PICCHI, V.; SILVA, E. O. T. R.; SOUZA, S. L. P. de; BALIAN, S. C. Isolamento e identificação de Listeria spp, em quartos dianteiros de bovinos desossados. Higiene Alimentar, São Paulo, v.13, n.63, p.38-42, 1999.

ROCOURT, J. Listeria monocytogenes: the state of the science. Dairy, Food and Environmental Sanitation, Ames, v.14, p.70-82, 1994.

RYSER, E. T.; MARTH, E. H. Listeria, listeriosis and food safety. New York: Marcel Dekker, 1991. 738p.

RYSER, E. T. The state of Listeria : where have we been and where are we going? Dairy, Food and Environmental Sanitation, Ames, n.19, p.828, 1999.

SCHUCHAT, A.; DEAVER, K.; GER, J. D. Role of foods in sporadic listeriosis. I. Case control study of dietary risk factors. Journal of the American Medical Association, Chicago, v.267, n.15, p.2041-2045, 1992.

SCHWARTZ, B.; CIESIELSKI, C. A.; BROOME, C. V.; GAVENTA, S.; BROWN, G. R.; GELLIN, B. G.;
HIGHTOWER, A. W.; MASCOLA, L. Association of sporadic listeriosos with consumption of uncooked hot dogs and undercooked chicken. Lancet, Minneapolis, v.2, p.779-782, 1988 .

SNYDER JR.; O. P. HACCP-TQM for retail and food service operations. Advances in Meat Research Series, New York, v.10, p.230-299, 1995.

SILVA, I. M. M.; ALMEIDA, R. C. C.; ALVES, M. A. O.; ALMEIDA, P. F. Occurrence of Listeria spp. in critical control points and the environmental of Minas Frescal cheese processing. International Journal of Food Microbiology, Amsterdam, v.81, p.241-248, 2003.

SILVA, M. C. D.; HOFER, E.; TIBANA, A. Incidence of Listeria monocytogenes in cheese produced in Rio de Janeiro, Brazil. Journal of Food Protection, Des Moines, v.61, p.354-256, 1998.

SWAMINATH, B.; ROCOURT, J.; BILLE, J. Listeria. In: MURRAY,P.R.;BARON,E. J.; PFALLER, M. A.; TENOVER, F. C.; YOLKEN, R. H.(Ed.). Manual of Clinical Microbiology. 6. ed. Washington: ASM Press; 1995. p.341-348.

UNITED STATES DEPARTAMENT OF AGRICULTURE. Food Safety and Inspection Service. Pathogen Reduction / Hazard Analysis and Critical Control Point (HACCP) Systems / Specific Sample Collection Procedure CRF Part 304. Rules and Regulations. Federal Register, Washington, v.61, n.144, p.38931, July, 1996.

WALDROUP, A. L. Contamination of raw poultry with pathogens. World's Poultry Science Journal, Mount Morris, v.52, p.7-25, 1996.

WILKINS, P. O.; BOURGEOIS, R.; MURRAY, R. G. E. Psychrotrophic properties of L. monocytogenes. Canadian Journal of Microbiology, Ottawa, v.18, p.543$547,1972$. 